\title{
Perubahan Tata Guna Lahan Sekitar Danau Galela
}

\author{
Hendro Christi Suhry ${ }^{1}$, Tri Retnaningsih Soeprobowati1,2 dan Jumari² \\ ${ }^{1}$ Departement Biologi, Fakultas Sains dan Matematika, Universitas Diponegoro \\ 2Sekolah Pascasarjana, Universitas Diponegoro; e-mail: trsoeprobowati@live.undip.ac.id
}

\begin{abstract}
ABSTRAK
Danau Galela adalah salah satu sumberdaya perairan tawar terbesar di Provinsi Maluku Utara yang mengalami permasalahan degradasi lahan dari lahan hutan dan perkebunan menjadi lahan peruntukan. Hal ini berpengaruh terhadap catchment area dan badan air danau. Penelitian ini bertujuan untuk mengetahui kondisi vegetasi dan tataguna lahan pada Daerah Tangkapan Air (DTA) Danau Galela. Metode yang digunakan dalam penelitian ini adalah membuat plot kuadrat untuk vegetasi pohon, tiang, pancang dan semai dilanjutkan menghitung indeks nilai penting (INP) vegetasi, wawancara dan maapping gambar menggunakan citra landsat. Berdasarkan analisis INP vegetasi disekitar danau galela didominasi oleh Cocos nucifera L., Ficus variegata Blume, Arenga pinnata Merr., Kleinhovia hospita L., Eleusine indica, Paspalum conjugatum dan Cyperus rotundus. Berdasarkan citra lansat luasan total daerah tangkapan air Danau Galela adalah 3873,81 ha Tata guna lahan sekitar kawan berdasarkan hasil wawancara telah berubah dibandingkan 20 hingga 30 tahun lalu.
\end{abstract}

Kata kunci: DTA, Vegetasi, Tataguna lahan, Citra landsat, Galela

\begin{abstract}
Lake Galela is one of the largest sources of funds in North Maluku Province, degradation of land from forests and plantations around lake has been problem. This affected the catchment area and water bodies. This study discusses the vegetation and land catchment area. The method used in this research included quadratic plot for vegetation of trees, poles, saplings and seedlings, calculate the vegetation importance index (INP) of vegetation, interviews and mapping using landsat images. Based on the analysis of INP vegetation of lake galela dominated by Cocos nucifera L., Ficus variegata Blume, Arenga pinnata Merr., Kleinhovia hospita L., Eleusine indica, Paspalum conjugatum and Cyperus rotundus. Based on the Landsat imagery the total area of Lake Galela's catchment is 3873.81 ha The land use around the lake has changed compared to 20 to 30 years ago.
\end{abstract}

Keywords: Catchment area, Vegetation, Land use, Landsat, Galela

Citation: Suhry, H.C., Soeprobowati, T.R., dan Jumari. (2020). Perubahan Tata Guna Lahan Sekitar Danau Galela. Jurnal Ilmu Lingkungan, 18(1), 140-145, doi:10.14710/jil.18.1.140-145

\section{Pendahuluan}

Danau Galela memiliki fungsi yang penting bagi ekosistem dan memiliki keanekaragaman hayati yang tinggi. Abdulla (2005) dalam penelitiannya mengungkapkan Danau Galela adalah danau terbesar di wilayah Galela dengan luas mencapai 250 ha, meliputi dua kecamatan, Kecamatan Galela dan Galela Barat. Danau ini dikelilingi 9 desa diantaranya Seki, Togawa, Sukonora, Igobula, Bale, Soatabaru, Dokolamo, Duma dan Goatalamo.

Seiring meningkatnya pertumbuhan penduduk, kegiatan pembangunan yang tidak berkelanjutan, urbanisasi yang tidak terencana, ekspansi pertanian yang agresif, perubahan iklim, dan perubahan terkait dalam penggunaan lahan dan tutupan lahan menyebabkan tekanan terhadap tata guna lahan berdampak pada penurunan keanekaragaman di sekitar danau
Perubahan tata guna lahan mempengaruhi perubahan lingkungan global yang memiliki dampak terhadap kelangsungan hidup manusia (Lasanta et al., 2006; Bryan, 2013; Costanza et al., 2014). Meningkatnya pembukaan lahan untuk aktivitas pertanian, urbanisasi yang luas, deforestasi dan aktivitas sehari-hari umat manusia menghasilkan perubahan temporal dan spasial dalam penggunaan lahan yang akan mempengaruhi Danau Galela seperti regulasi hidrologi dan erosi tanah (Rawat \& Kumar, 2015; Oyodetun, 2019). Pada skala lokal, perubahan penggunaan lahan mempengaruhi Daerah sekitar danau, sumber daya iklim mikro, tabel air tanah, proses degradasi lahan dan keanekaragaman hayati (Gong et al.,2015). Namun, yang utama antara lain adalah kurangnya kebijakan penggunaan lahan yang tepat (Teka et al., 2013).

Dengan meningkatnya pertumbuhan populasi secara global, akan meningkatkan tekanan terhadap 
alam dan menyebabkan adanya perubahan tata guna lahan (Islam et al., 2017). Pertumbuhan penduduk mempengaruhi laju pembangunan di catchment area serta luasan perkebunan warga yang makin bertambah, menyebabkan ahli fungsi lahan yang merusak vegetasi asli disekitar danau. Jenis vegetasi asli mata air dan daerah serapan menjadi tergantikan. Tata guna lahan yang tidak efektif berdampak pada penurunan kualitas perairan Danau Galela.

Perubahan tata guna lahan sangatlah penting untuk diteliti karena mampu memberikan pemahaman mengenai pengelolaan lingkungan (Rawat\&Kumar, 2015). Vegetasi di sekitar danau juga sangat penting dan tidak dapat pisahkan dengan kualitas perairan danau. Mempelajari vegetasi di sekitar danau dapat memberikan informasi mengenai keterkaitan antara vegetasi dengan kualitas perairan. (Vainu dan Terasmaa, 2014; Finstad et al., 2017). Kebutuhan masyarakat akan ketersediaan lahan yang kian bertambah seiring dengan pertumbuhan penduduk mempengaruhi laju pembangunan di catchment area serta luasan perkebunan warga yang makin bertambah, menyebabkan ahli fungsi lahan yang merusak vegetasi asli disekitar danau. Jenis vegetasi asli mata air dan daerah serapan menjadi tergantikan. Tata guna lahan yang tidak efektif berdampak pada penurunan kualitas perairan Danau Galela. Penelitian ini bertujuan menganalisis perubahan tata guna lahan di sekitar Danau Galela.

\section{Study Area}

Sampling vegetasi pada empat stasiun di sekitar daerah tangkapan air (DTA) Danau Galela. Pengambilan data faktor fisik area vegetasi meliputi letak geografis, posisi ketinggian lokasi, kelembapan dan $\mathrm{pH}$ tanah.

\subsection{Pengumpulan data}

Penentuan titik sampling untuk pengamatan vegetasi di sekitar danau berdasarkan kondisi dan tata guna lahan di sekitar Danau Galela. Titik sampling mewakili hutan alami, hutan tanam (area perkebunan) yang dibagi dalam empat stasiun pengamatan. Pengamatan struktur dan komposisi vegetasi dimulai dari titk 0 hingga radius $500 \mathrm{~m}$ ke arah daratan, Analisis vegetasi menggunakan metode plot kuadrat. Dari setiap stasiun pengamatan diambil sampel vegetasi sesuai fase pertumbuhan vegetasi 1 $\mathrm{m} \times 1 \mathrm{~m}$ untuk tingkatan semai, $5 \mathrm{~m}$ x $5 \mathrm{~m}$ untuk pancang, $10 \mathrm{~m} \mathrm{x} 10 \mathrm{~m}$ untuk tiang dan $20 \mathrm{~m}$ x $20 \mathrm{~m}$ untuk pohon. Pada setiap stasiun diambil 6 plot kuadrat, dilakukan pencatatan nama jenis, jumlah individu, diameter untuk tingkatan pancang, tiang dan pohon, sedangkan untuk semai dihitung jumlah dan persen penutupan.

\subsection{Analisis data}

Perhitungan indeks nilai penting menggunakan rumus oleh Kusmana (1997), Semakin besar INP suatu spesies berarti semakin besar peran spesies tersebut dalam komunitas Data vegetasi yang telah terkumpul kemudian dianalisis untuk mengetahui kerapatan jenis, kerapatan relatif, dominansi jenis, dominansi relatif, frekuensi jenis dan frekuensi (Kusmana, 1997). Berdasarkan nilai INP kemudian di dideskripsikan kondisi vegetasi dan tingkat dominansi atau penguasaan spesies-spesies dalam suatu komunitas tumbuhan di sekitar daerah tangkapan air Danau Galela.

Visualisasi penggunaan lahan terkini dibuat menggunakan program Arcgis 10.3 untuk memetahkan wilayah berdasarkan pemanfaatan lahan dan kondisi terkini daerah tangkapan air Danau Galela.

\section{Hasil dan Pembahasan}

\subsection{Perubahan fungsi tata guna lahan}

Pembagian penggunaan lahan di catchment area Danau Galela terdiri atas lahan perkebunan, hutan, pemukiman, perladangan dan tutupan eceng gondok, Berdasarkan hasil perhitungan diketahui bahwa luasan total daerah tangkapan air Danau Galela adalah 3873,81 ha.

Persentase area perkebunan 73,34 \%, sedangkan area hutan 11,12 \%, area ladang 0,05 \%,area pemukiman 4,87\% dari total luasan daerah tangkapan air. Total luasan Danau 390 ha atau 10,17\% dari total luasan daerah tangkapan air, sementara luas tutupan eceng gondok 22,1\% dari luas total Danau (Gambar 2)

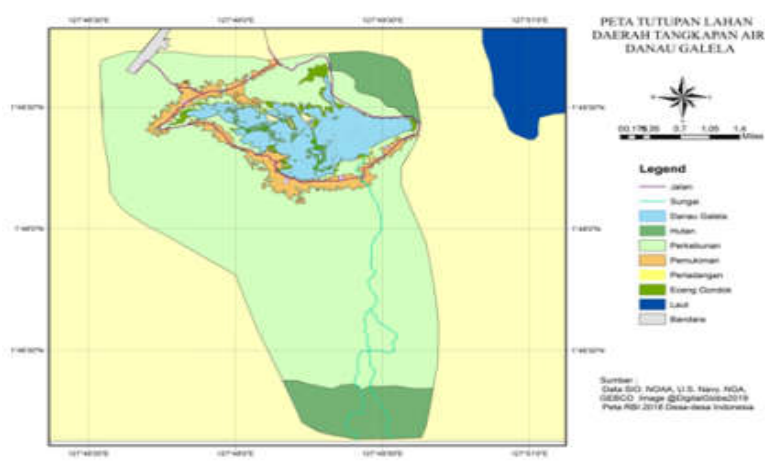

Gambar 1. Peta Perubahan Tata Guna Lahan Danau Galela 2019

Perkembangan budidaya mengalami peningkatan dari 2 keramba pada tahun 2017 menjadi 206 keramba pada tahun 2018. Catchment area diperuntukan bagi lahan pertanian, perkebunan dan pemukiman penduduk.

Hasil identifikasi spesies tumbuhan disekitar Danau Galela, pada tingkat pohon terdapat 35 spesies dari 19 famili, pada tingkat tiang ditemukan 23 spesies dari 14 famili, pada tingkatan pancang ditemui 
19 spesies dari 13 famili dan pada tingkatan semai ditemui 32 spesies dari 22 famili.

Indeks Nilai Penting (INP) dihitung untuk menggambarkan peranan suatu jenis tumbuhan dalam komunitas. INP yang tinggi sangat mempengaruhi suatu komunitas tumbuhan. Berdasarkan hasil perhitungan INP strata pohon, diketahui bahwa Cocos nucifera L. dan Myristica fragrans memiliki nilai tertinggi(Tabel.1)

Tabel 1. Hasil perhitungan indeks nilai penting (INP) untuk strata pohon.

\begin{tabular}{|c|c|c|c|c|c|c|}
\hline \multirow{2}{*}{ No } & \multirow{2}{*}{ Nama Lokal } & \multirow{2}{*}{ Nama Ilmiah } & \multicolumn{4}{|c|}{ Index Nilai Penting (\%) } \\
\hline & & & ST I & ST II & ST III & ST IV \\
\hline 1 & Ngededoro/ Katimaha & Kleinhovia hospita L. & 13.96 & & 20.05 & 5.09 \\
\hline 2 & Goriotho/ Kedondong & Spondias dulcis Park & 6.58 & 6.64 & 7.09 & 6.81 \\
\hline 3 & Toro/ Gondangputih & Ficus variegata Blume & 37.59 & & 34.07 & 21.35 \\
\hline 4 & Dinga/ Benda & Artocarpus elasticus Reinw. Ex & 14.04 & 18.93 & 12.33 & \\
\hline 5 & Samoma/ Arabereteh & Ficus tinctoria G.Forst. & 16.48 & & & \\
\hline 6 & Seho/ Aren & Arenga pinnata Merr. & 18.28 & 18.65 & 19.63 & 30.81 \\
\hline 7 & Igo/ Kelapa & Cocos nucifera L. & 17.5 & 63.88 & 14.39 & 29.01 \\
\hline 8 & Kapok/ Kapukrandu & Ceiba pentandra (L.) Gaertn & 11.43 & & & 10.36 \\
\hline 9 & Kelo/ Kelor & Moringa oleifera Lam. & 6.41 & & 6.83 & 5.09 \\
\hline 10 & Gosora/ Pala & Myristica fragrans Houtt. & 7.15 & 50.97 & & 18.58 \\
\hline 11 & Durian & Durio zibethinus Murray & 8.08 & & & 6.17 \\
\hline 12 & Ngaahe/ Matoa & Pometia pinnataJ.R.\& G.Forst & 16.07 & 18.47 & & 13.22 \\
\hline 13 & Waringin/ Beringin & Ficus benjamina L. & 19.18 & & 32.37 & \\
\hline 14 & Amo/Sukun & Artocarpus altilis (Park) Fosberg. & 13.29 & 18.39 & 18.66 & \\
\hline 15 & Kayu tolor/ Pulai & Alstonia scholaris R.Br. & 12.79 & & & 14.41 \\
\hline 16 & Ruki/ Melinjo & Gnetum gnemon L. & 3.47 & & & \\
\hline 17 & Pena/ Pinang & Areca catechu L. & 9.95 & 9.96 & & 16.68 \\
\hline 18 & Katapa/ Ketapang & Terminalia katapa & 11.21 & & & \\
\hline 19 & Wale Stinki/ Bacang & Mangifera foetida Lour. & 13.65 & & & \\
\hline 20 & Gufasa/ Kayubitti & Vitex cofassus Reinw.ex. Bl. & 8.9 & & & \\
\hline 21 & Niha/ Kenari & Canarium maluense Lautrb. & 13.65 & & & 11.05 \\
\hline 22 & Ngame/ Pohondahu & Dracontomelon dao Merr.Rolfe & 6.41 & 18.47 & & 10.36 \\
\hline 23 & Ulewe/ Pandanduri & Pandanus tectorius Park. ex Zucc. & 5.85 & & & 9.55 \\
\hline 24 & Bululawa/ Cengkih & Syzygium aromaticum (L.) Merr. L. M.P & 8.08 & & & \\
\hline 25 & Naka/ Nangka & Artocarpus heterophyllus Lam. & & 11.94 & & \\
\hline 26 & Gamkonora/ Cempedak & Artocarpus integer (Thunb.) Merr & & 7.37 & & 11.45 \\
\hline 27 & Lasa/ Langsat & Lansium domesticum Corrêa & & 11.54 & & \\
\hline 28 & Coklat/ Kakao & Theobroma cacao L. & & 31.04 & & \\
\hline 29 & Gora/ Jambubol & Syzygium malaccense (L.) Merr. & & 13.75 & & 11.45 \\
\hline 30 & Balibi/ Belimbing & Averrhoa carambola L. & & & 15.49 & 9.55 \\
\hline 31 & Jati & Tectona grandis Linn.f & & & 15.49 & 8.02 \\
\hline 32 & Ligua/ Angsana & Pterocarpus indicus Willd. & & & 31.36 & \\
\hline 33 & Wale/ Mangga & Mangifera indica $\mathrm{L}$. & & & 72.21 & 13.22 \\
\hline 34 & Gersen/ Kersen & Muntingia calabura L. & & & & 20.27 \\
\hline 35 & Kopi/ Kopi robusta & Coffea robusta L. Linden & & & & 17.49 \\
\hline
\end{tabular}

Vegetasi tingkat tiang pada stasiun I, Piper aduncum memiliki nilai indeks tertinggi tercatat mencapai 33,4 diikuti Ficus variegata dan F. Tinctoria masing-masing mencapai 30,5 (Tabel.2). Pada tingkatan ini Piper aduncum, F. variegata dan $F$. tinctoriadan Kleinhovia hospita memiliki peranan penting dalam mempengaruhi kondisi lingkungan sekitar danau.

Pada tingkatan pancang stasiun I, Tetrameles nudiflora tercatat memiliki nilai indeks tertinggi yaitu mencapai 76.12. pada stasiun II Carica papaya memiliki nilai indeks tertinggi mencapai 60.2. Tetrameles nudiflora, Carica papaya, Musa paradisiaca dan Ficus septica merupakan jenis tumbuhan yang sangat mempengaruhi kestabilan lingkungan pada tingkatan pancang. Sedangkan pada tingkatan semai nilai INP tertinggi yaitu: E. indica, $P$. conjugatum dan C. Rotundus (Tabel.3).

Hasil analisis terhadap jenis vegetasi yang ditemui pada beberapa tingkatan, menunjukan bahwa F. variegata dan Kleinhovia hospita dijumpai pada strata pohon, tiang dan pancang. Hal ini mengindikasikan bahwa tumbuhan tersebut memiliki regenerasi pertumbuhan yang baik sehingga potensial untuk dikembangkan sebagai tanaman vegetasi konservasi kawasan. 
Tabel 2. Hasil perhitungan indeks nilai penting (INP) untuk strata tiang.

\begin{tabular}{|c|c|c|c|c|c|c|}
\hline \multirow{2}{*}{ No } & \multirow{2}{*}{ Nama Lokal } & \multirow{2}{*}{ Nama Ilmiah } & \multicolumn{4}{|c|}{ Index Nilai Penting (\%) } \\
\hline & & & ST I & ST II & ST III & ST IV \\
\hline 1 & Bidorika/ Sirihan & Piper aduncum L. & 33.4 & & & 24.2 \\
\hline 2 & Gawaya/ Jambubiji & Psidium guajava $\mathrm{L}$. & 15.32 & 22.7 & & 20.9 \\
\hline 3 & Ngogu/Jarak & Ricinus communis $\mathrm{L}$. & 12.8 & & 22.1 & \\
\hline 4 & Samoma/ Arabereteh & Ficus tinctoria G.Forst. & 30.5 & & & \\
\hline 5 & Tapaya/ Pepaya & Carica papaya L. & 23.6 & 36.4 & 32.3 & \\
\hline 6 & Ngededoro/ Katimaha & Kleinhovia hospita L. & 16.2 & 75.2 & 79.27 & 41.3 \\
\hline 7 & Bia batu/ Bambu & Bambusa vulgaris Schrad. ex J.C. & 25.9 & 41.6 & 39.4 & \\
\hline 8 & Balibi popululu/ Belimbing & Averrhoa bilimbi L. & 17.2 & 52.7 & & \\
\hline 9 & Kelo/ Kelor & Moringa oleifera Lam. & 26.6 & & & \\
\hline 10 & Ngame/ Pohondahu & Dracontomelon dao Merr.Rolfe & 12.8 & & & \\
\hline 11 & Amo/Sukun & Artocarpus altilis (Park) Fosberg. & 13.5 & & & \\
\hline 12 & Dinga/ Benda & Artocarpus elasticus Reinw. Ex & 17.2 & & & \\
\hline 13 & Toro/Gondangputih & Ficus variegata Blume & 30.5 & & & \\
\hline 14 & Balacai/ Jarakpagar & Jatropha curcas L. & & 52.7 & & 32.9 \\
\hline 15 & Wale/ Manga & Mangifera indica $\mathrm{L}$. & & 43.8 & & \\
\hline 16 & Naka walanda/ Sirsak & Annona muricata $\mathrm{L}$. & & 27.6 & & 31.8 \\
\hline 17 & Jati & Tectona grandis L.f. & & & 19.6 & \\
\hline 18 & Kapu/ Pohonbenaung & Octomeles sumatrana & & & 23.5 & 24.3 \\
\hline 19 & Seho/ Aren & Arenga pinata (Wurmb) Merr. & & & 30.1 & 22.2 \\
\hline 20 & Buanona/ Sirkaya & Annona squamosa $\mathrm{L}$. & & & 53.7 & \\
\hline 21 & Kasbi Karet/ Ketelakaret & Manihot glaziovii Müll.-Arg. & & & & 30.5 \\
\hline 22 & Salak/ Salak & Salacca zalacca (Gaert.) Voss. & & & & 36.3 \\
\hline 23 & Wama/ Jerukmanis & Citrus sinensis (L.) Osbeck & & 30 & & 35.5 \\
\hline
\end{tabular}

Tumbuh-tumbuhan disekitar Danau Galela memiliki potensi konservasi kawasan dan air. Pada tumbuhan tingkatan semai $E$. indica, $P$. conjugatum dan $C$. rotundus. memiliki potensi sebagai tumbuhan penutup tanah (Ground cover) yang baik dalam hal meredam laju hempasan air hujan sehingga dapat meminimalisir erosi. Selain itu akar yang dimiliki membantu mengikat tanah,mengingat catchment area Danau Galela memiliki struktur tanah berpasir yang labil sehingga mudah terbawa air. Cocos nucifera, Arenga pinnata, Bambusa sp, Mangifera indica, Kleinhovia hospita, dan Musa paradisiaca memiliki fungsi sebagai tanaman konservasi air.

Beberapa jenis tumbuhan konservatif kawasan dan air yang termasuk dalam famili Moraceae seperti F. Variegata, F. benjamina, F. tinctoria, A.arpus elasticus, A. heterophyllus, A. altilis dan F. septica. Kelompok tumbuhan famili Moraceaeyang ditemukan di sekitar Danau Galela rata-rata memiliki sistem perakaran yang mendukung dalam penyerapan air. Ulfah dan Sulistyawati (2015) menyatakan kelompok ini memiliki kemampuan untuk menyerap air dalam jumlah banyak (hydraulicconductance).

Akar tumbuhan berupa akar tunggang yang dalam dan melebar sehingga mampu mengikat tanah serta meminimalisir resiko lahan mengalami erosi (Fiqa et al 2005; Ridwan et al 2015). Selain itu tutupan tajuk yang dimiliki tumbuhan anggota famili Moraceae berperan dalam perlindungan dan penutupan kawasan. Tutupan tajuk meredam kekuatan tetesan air hujan yang menetes secara maksimal sehingga infiltrasi air ke tanah lebih baik dan mengurangi kerusakan pada lapisan permukaan tanah oleh air (Soejono, 2012; Sihotang, 2012).

Potensi konservasi kawasan juga dimiliki oleh Kleinhovia hospita. Tipe perakaran tunggang yang dimiliki Tumbuhan ini memilki potensi penahan tanah yang tidak dapat diragukan. Hal ini terbukti dengan keberadaan tumbuhan ini pada beberapa lahan dengan kemiringan signifikan di sisi Danau Galela maupun sepanjang pinggiran sungai. (Utami et al, 2016; Wiryani et al, 2018).

Kawasan sekitar Danau Galela dulunya merupakan kawasan yang didominasi populasi kelapa, pala dan cengkih, selain itu banyak pohon dengan ukuran besar seperti meranti, linggua, gufasa, benda, sukun dan pulai. Tepian danau dikelilingi tumbuhan bambu, pada bagian selatan tepatnya di Desa Sukonora dan Igobula (desa dengan jumlah pemukiman terpadat dan terdekat dengan danau) didominasi oleh tumbuhan "nguusu" (Imperata cylindrica).

Kondisi vegetasi di sekitar DTA telah mengalami perubahan menurut $93,7 \%$ responden. Perubahan yang terjadi memang tidak menyeluruh tetapi terdapat beberapa jenis vegetasi telah mengalami degradasi hingga ada yang hilang. Tumbuhan bambu dahulu menutupi $90 \%$ pinggiran danau, sekarang berkurang drastis. Pada badanair terdapat tumbuhan teratai, sekarang tidak ditemukan sama sekali. Pada beberapa tempat di sekitar danau, beberapa vegetasi tingkatan pohon dengan ukuran diameter $>4$ meter berkurang. 
Sekitar tahun 1960 masyarakat mulai membangun pemukiman yang dekat dengan tepian danau. Tahun 2000 wilayah Galela mengalami peristiwa konflik kemanusiaan sehingga banyak pemukiman yang hancur. 1 tahun berselang pembangunan kembali dilakukan dan mengalami kemajuan yang pesat hingga saat ini. Tahun 2004 budidaya keramba dimulai dengan konsep keramba tancap dan berkembang pesat, hingga sekarang telah banyak keramba apung disekitar danau. Bersamaan dengan masuknya aktifitas budidaya, beban danau ditambah dengan tumbuhan ecenggondok yang didatangkan dari Danau Tondano untuk pakan ikan dan tujuan memperindah danau. Kenyataannya introduksi ecenggondok mematikan populasi tumbuhan teratai di kawasan danau Tahun 2010 mulai dibangun tempat makan terapung dan beberapa tempat makan permanen di tepian danau yang berkembang pesat hingga sekarang.

Tabel 3. Hasil perhitungan indeks nilai penting (INP) untuk strata semai

\begin{tabular}{|c|c|c|c|c|c|c|}
\hline \multirow{2}{*}{ No } & \multirow{2}{*}{ Nama Lokal } & \multirow{2}{*}{ Nama Ilmiah } & \multicolumn{4}{|c|}{ INP (\%) } \\
\hline & & & ST I & ST II & ST III & ST IV \\
\hline 1 & Hutugamu/Sidaguri & Sida rhombifolia L. & 7.12 & 6.47 & 12.19 & 8.09 \\
\hline 2 & Kokaleda/ Rumputkerbau & Paspalum conjugatum P.J. Bergius & 14.23 & 33.19 & 30.46 & 17.74 \\
\hline 3 & Maimosa/ Putrimalu & Mimosa pudica $\mathrm{L}$. & 7.12 & 19.4 & & 8.09 \\
\hline 4 & Kamimaboci/ Rumput pinto & Arachis pintoi Krapov. W.C.Greg & 9.8 & & & 11.19 \\
\hline 5 & Lupu magaumi & Diplazium dilatatum & 7.12 & 8.76 & & 8.09 \\
\hline 6 & Takiu/ Rumputteki & Cyperus rotundus $\mathrm{L}$. & 14.23 & 17.74 & & 26.45 \\
\hline 7 & Pardop/ Rumputbelulang & Eleusine indica (L.) Gaertn. & 26.68 & 21.91 & 29.45 & 25.82 \\
\hline 8 & Cinga- cinga/ Bungawedelia & Wedelia trilobata (L.) Hitchc & 9.8 & 10.85 & 10.49 & 11.19 \\
\hline 9 & Bete/ Talas & Colocasia esculenta (L.) Schott & 7.12 & & & 6.22 \\
\hline 10 & Ence-ence/ Pecutkuda & Stachytarpheta indica (L.) Vahl. & 6.23 & & & 7.15 \\
\hline 11 & Buang Putri/ Markisakonyal & Passiflora ligularis Juss. & 9.8 & & & 11.19 \\
\hline 12 & Ngusu/ Alang-alang & Imperata cylindrica (L.) Raeusch & 9.8 & & & 13.06 \\
\hline 13 & Ngabalo/ Uwiungu & Dioscorea alata $\mathrm{L}$. & 12.47 & & & \\
\hline 14 & Kalapa honenge/ Sengketan & Achyranthes aspera $\mathrm{L}$. & 6.23 & 8.76 & & 7.15 \\
\hline 15 & Boki ma gopolo/ Anting-anting & Acalypha australis Linn & 10.68 & & & 12.13 \\
\hline 16 & Dodo Polo/ Rumput knop & Hyptis capitata Jacq. & 7.12 & 7.61 & 14.89 & 8.09 \\
\hline 17 & Kuge/ Mantangan & Merremia peltata (Roxb.) Merr. & 8.91 & & 4.4 & \\
\hline 18 & Sosoro/Jelatang & Laportea aestuans (L.) Chew & 14.24 & 6.47 & & \\
\hline 19 & Lage-lage/ Pakupedang & Nephrolepis bisserata (Sw.) Schott & 5.35 & & 20.98 & 6.22 \\
\hline 20 & Ecenggondok & Eichhornia crassipes (Mart.) Solms & & 4.38 & & \\
\hline 21 & Dagameme/Ciplukan & Physalis minima $\mathrm{L}$. & & 7.61 & & \\
\hline 22 & Sapoare/ Bandotan & Ageratum conyzoides L. & & 10.85 & & \\
\hline 23 & Kastorol/ Kate emas & Euphorbia heterofpylla L. & & 12 & & \\
\hline 24 & Manjanga/ Bayamkakap & Amaranthus hybridus L. & & 10.85 & & \\
\hline 25 & Biabebe/ Pacar air & Impatiens balsamina $\mathrm{L}$. & & & 4.4 & \\
\hline 26 & Bido/ Sirih & PiperbetleL. & & & 8.8 & \\
\hline 27 & blakang babuku/ Meniran & Phyllanthus niruri L. & & & 4.4 & \\
\hline 28 & Gurati/ Kunyit & Curcuma longa $\mathrm{L}$. & & & 8.8 & \\
\hline 29 & Goraka/Jahe & Zingiber officinale Roscoe & & & 10.49 & \\
\hline 30 & Gothom/ Paku sayur & Diplazium esculentum (Retz.) C. Presl & & & 14.89 & \\
\hline 31 & Kasomagina/ Jatitiongkok & Senna obtusifolia (L.) Irwin \& Barneby & & & 8.8 & \\
\hline 32 & Loloro/ Katang-katang & Ipomoea pes-caprae (L.) R. Br. & & & 4.4 & \\
\hline
\end{tabular}

\section{Kesimpulan}

Berdasarkan hasil penelitian terdapat perubahan tata guna lahan pada Daerah Tangkapan air disekitar Danau Galela apabbila dibandingkan dengan 20 hingga 30 tahun lalu. Berdasarkan citra lansat luasan total daerah tangkapan air Danau Galela adalah 3873,81 ha dan mengalami perubahan fungsi menjadi lahan hutan, ladang, perkebunan, pemukiman dan peningkatan enceng gondok. Perubahan tata guna lahan disekitar area danau mampu menyebabkan potensial longsor. Sedangkan hasil dari analisis Struktur dan komposisi vegetasi di sekitar Danau Galela terdiri atas pohon 35 spesies, strata tiang 23 spesies, strata pancang 19 spesiesdan 144 strata semai 32 spesies. INP tertinggi pada strata pohon Cocos nucifera L. dan pala (Myristica fragrans Houtt), INP tertinggi pada strata tiang (Kleinhovia hospita L. dan Bambusa vulgaris), strata pancang (Ficus septica Burm.f. dan Piper aduncum .L.), dan strata semai (Paspalum conjugatum P.J. Bergius dan Eleusine indica (L.) Gaertn.

\section{DAFTAR PUSTAKA}

Abdullah A, 2005. Studi Bioekologi Ikan Air Tawar Di Danau Galela Kabupaten Halmahera Provinsi Maluku Utara, Bogor: Institut Pertanian Bogor 
Bryan, B.A. 2013. Incentives, land use, and ecosystem services: Synthesizing complex linkages. Environmental Science \& Policy, 27, 124-134

Costanza, R., de Groot, R., Sutton, P., Van der Ploeg, S., Anderson, S. J., Kubiszewski, I. Turner, R. K. 2014. Changes in the global value of ecosystem services. Global Environmental Change, 26, 152-158.

Finstad, AG., Nilsen, EB., Hendrichsen, DK., Schmidt, NM., 2017. Catchment vegetation and temperature mediating trophic interactions and production in plankton evaluate an alternative management scenario in abandoned Mediterranean mountain areas. Landscape and Urban Planning, 78, 101-114.

Fiqa, AP., Arisoesilaningsih, E dan Soejono., 2005. Konservasi Mata Air DAS Brantas Memanfaatkan Diversitas Flora Indonesia. Prosiding seminar Basic Science II. Universitas Brawijarya, Malang.

Gong, J., Yang, J., \& Tang, W. 2015. Spatially explicit landscape-level ecological risks induced by land use and land cover change in a national ecologically representative region in China. International Journal of Environmental Research and Public Health, 12, 14192-14215.

Islam, K., Jashimuddin, M., Nath, B., \& Nath, TK. 2017. Land use classification and change detection by using multitemporal remotely sensed imagery: The case of chunati wildlife sanctuary, Bangladesh. The Egyptian Journal of Remote Sensing and Space Sciences, in press. doi:10.1016/j.ejrs.2016.12.005.

Lasanta, T., González-Hidalgo, JC., Vicente-Serrano, S M., \& Sferi, E.2006. Using landscape ecology to evaluate an alternative management scenario in abandoned Mediterranean areas. Landscape ad Urban Planning, 78: 101-114.

Oyodetun, TDT. 2019. Land use change and classification in Chaohu lake catchment from multi temporal remotely sensed images. Geology, Ecology and Landscape. 3:3745

Rawat, JS., \& Kumar, M. 2015. Monitoring land use/cover change using remote sensing and GIS techniques: A case study of Hawalbagh block, district Almora, Uttarakhand, India. The Egyptian Journal of Remote Sensing and Space Sciences, 18, 77-84

Ridwan, M dan Pamungkas, D. W, 2015. Keanekaragaman Vegetasi Pohon di Sekitar Mata Air di Kecamatan Panekan, Kabupaten Magetan, Jawa Timur. Prosiding Seminar Masyarakat Biodiversitas Indonesia, 1:13751379

Sihotang, 2012. Model Konservasi Sumberdaya Air Danau Toba, Jurnal Pengelolaan Sumberdaya Alam Dan Lingkungan, 2(2):65-72

Soejono, 2012. Composition of Trees Grown Surrounding Water Springs at Two Areas in Purwosari, Pasuruan, East Java. The Journal of Tropical Life Science. 2(2):110-118.

Teka, K., Van Rompaey, A., \& Poesen, J. 2013. Assessing the role of policies on land use change and agricultural development since 1960s in northern Ethiopia. Land Use Policy, 30, 944-951. doi:10.1016/j.landusepol.2012.07.005

Ulfah, S dan Sulistyawati, E, 2018. Perubahan Struktur Vegetasi Pada Sistem Perladangan Gilir Balik Masyarakat Dayak Pitap Kalimantan Selatan, Jurnal Bumi Lestari, 18(2)63-74

Utami,S, Anggoro S, Soeprobowati T. R, 2016, Struktur Komunitas Tumbuhan Bawah Herba Di Hutan Lindung Pulau Panjang Jepara Jawa Tengah, Prosiding Seminar Nasional Hasil-Hasil Penelitian Pascasarjana, 149-152

Vainuu, M and Terasmaa J, 2014. Changes In Climate, Catchment Vegetation And Hydrogeology As The Causes Of Dramatic Lake-Level Fluctuations In The Kurtna Lake District, NE Estonia, Estonian Journal of Earth Sciences 63(1):45-61

Wiryani, E., Murningsih, Jumari, 2018. The abundance and importance value of tree in Sendang Kalimah Toyyibah" surrounding and its implication to the spring, IOP Conf. Series: Journal of Physics: Conf. Series 1 